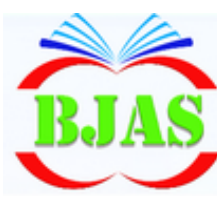

ISSN $1814-5868$
Available online at $\mathrm{http}: / /$ bajas.edu.iq

College of Agriculture, University of Basrah

DOi:10.21276/basjas

\section{Basrah \\ Journal of \\ Agricultural \\ Sciences}

\title{
Short Communication: Scanning of Processed Food Contaminating Fungi and Determine the Potential Aflatoxigenic type
}

\author{
Layla A. Benyan \& Azhar A. Alhaddad* \\ Department of Plant Protection, College of Agriculture, University of Basrah, Iraq \\ *Corresponding author e-mail: azhar1982ha@gmail.com
}

Received 15 March 2019; Accepted 24 May 2019; Available online 31 October 2019

\begin{abstract}
This study was conducted in the plant protection dept., College of Agriculture, University of Basrah to investigate the food contaminated fungi in several food products involved potato chips, pasta, and popcorn to specify the potential aflatoxigenic species. Eight samples of food products were randomly collected from local market included two samples of pasta, 5 samples potato chips, and one sample of popcorn. The primary isolation was performed on potato dextrose agar (PDA) in $9 \mathrm{~cm}$ Petri dishes; the isolated fungi were purified then diagnosed morphologically. The isolation results revealed a presence of several species within three main fungal genera, which included, Penecillium sp., Alternaria alternata, Aspergillus flavus, A. niger, A. alliaceus, A. candidus, A. fumigatus and A. sclerotiorum in prevalence percentages $43.75,35.00,18.75,27.50,5.64,3.75,3.75,3.75,3.75 \%$ respectively and frequency percentage $7.15,2.60,9.07,10.69,0.46,1.28,0.46,1.00 \%$ respectively. A. flavus was obtained to examine its ability to produce Aflatoxin using ammonia vapor test. The results revealed that nine isolates of A. flavus showed a possible ability to produce Aflatoxin B1.
\end{abstract}

Keywords: Aflatoxins, Contamination, Fungi.

\section{Introduction}

The fungi are well known as pathogenic microorganisms that contaminating most of the economic crop causing direct and/or indirect damages. A twenty-five percent of the world's food crops and their products are contaminated with mycotoxin (Smith et al, 1994).
Mycotoxins are secondary metabolites produced by several genera of fungi like Aspergillus spp., Pencilium spp. and Fusarium spp., which are spread all over the world as natural contaminants in numerous commodities of plant origin, especially in cereals grains, nuts, oil seeds, fresh and dried fruits, vegetables, cocoa, coffee beans, beer, 
and species. Also, they can be found in animal-derived food (if animals consumed a contaminated feed), namely meat, eggs and milk (Bryden, 2012; Marin et al., 2013). More than 4.5 million people in developing countries are exposed to the Aflatoxins, which had a great interest as a hazardous food contaminant especially in developing countries (Bhat \& Krishnamachari, 1977; Makun et al., 2010). The consumption of foods contaminated with mycotoxins can affect human and animal health and causes several diseases such as urinary tract infection, immuno-deficiency, and genetic abnormalities lead to congenital malformations (Bhat \& Vasanthi 2003, Carvajal, 2015).

Climate represents the key factor for fungal occurrence and mycotoxin production. Mycotoxin is climate-dependent compounds, but several factors can affect their presence, such as bioavailability of micronutrients, insect damage making it complex and multifactor phenomenon (Milani, 2013)

Indeed, the toxicity of mycotoxin cannot be confirmed precisely in natural contaminated food and feeds due to complicated infection with several toxigenic fungi that produce a mixture of mycotoxins that leads to generate a synergistic effect, which can cause activation or inhibition effect.

Aflatoxins are the most important group of the mycotoxins that produced by Aspergillus spp., especially in the tropical areas, which are causes liver cancer and immune deficiency in humans and animals (Da Rocha et al., 2014). Aflatoxin B1 is the most important aflatoxins produced by Aspergilli, which is metabolized to M1 and P1 by hydrogenation, which is less toxic than the main toxin (Rustom et al., 1993).
The most important physical and chemical properties of aflatoxins are its yellowishwhite-colored, odorless and bitter, crystalline, dissolves in organic solutions and dissolve in water, give a phosphorescence color when exposed to ultraviolet light UV-resistant and low molecular weight (Reddy \& Farid, 2006) melting point and decomposition ranges from 237-320 ${ }^{\circ} \mathrm{C}$ (Rustom, 1997).

Mycotoxins are secondary metabolic products that react chemically to abisdihydrodifuran or tetrahydrobisfuran combined with cyclopentanone or alacton (Jaimez et al., 2000).

Aflatoxins are divided into two groups

a) Bisfuran-coumarin.

b) Bisfuran-coumarin-lactones.

(Rastogi et al., 2001, 2001, Nakai et al, 2008).

As a result of the poor storage of food and food products, human health will be affected, therefore the establishment of modern stores and careful handling of animals, their health and products in addition to control of fungi and its toxins, This study was designed to investigate the food associated fungi and presence of Aflatoxin B1 in the pasta and chips that are produced from wheat and corn according to the large consumption by children and adults.

\section{Materials \& Methods:}

\section{Sampling:}

The samples were collected randomly from local markets of Basrah governorate in $20^{\text {th }}$ of Oct. 2014, which were included chips (5 samples), popcorn (2 samples), and two samples of pasta. The samples were kept in refrigerator $\left(4^{\circ} \mathrm{C}\right)$ for next laboratory experiments. 
Benyan \& Alhaddad / Basrah J. Agric. Sci., 32 (Special Issue): 314-322, 2019

\section{The preparation of growing media}

\section{Potato dextrose agar (PDA)}

The PDA (extract of $200 \mathrm{~g}$ of potato, $20 \mathrm{~g}$ of glucose, $20 \mathrm{~g}$ of agar and the volume was completed to $1 \mathrm{~L}$ with distilled water) the medium was supported by chloramphenicol $\left(250 \mathrm{mg} \cdot \mathrm{l}^{-1}\right)$ then autoclaved at $121^{\circ} \mathrm{C}$ and 15 bar for $15 \mathrm{~min}$.

\section{Coconut Agar}

This medium was prepared according to Davis et al. (1967), by boiling $100 \mathrm{~g}$ of coconut powder $300 \mathrm{ml}$ of distilled water for $15 \mathrm{~min}$, the mixture was filtered by several layers of sterilized gauze and the filtrate was equilibrated to 600 mils with distilled water. The medium was autoclaved at $121^{\circ} \mathrm{C}$ and 15 bar for $15 \mathrm{~min}$.

\section{Czapex solution Czapek Solution Concentrate}

The solution was prepared according to Klich (2002) method: Sodium nitrate NaNo3, 30.0gm Potassium chloride $\mathrm{Kcl}$, $5.0 \mathrm{gm}$ Magnesium hydroxide sulfate MgSo4 .7H2o, 5.0 gm Hydrothermal sulphate FeSo4 .7H2o, 0.1 gm Hydrogen sulphate ZnSo4.7H2o, 0.1 gm Copper sulphate $\mathrm{CuSo} 4 \mathrm{Cu} 5 \mathrm{a}, 0.05$ gm, were dissolved in Distilled water and the solution equilibrated to $100 \mathrm{ml}$. The mixture was kept in the refrigerator until use, with good continues shaking to dissolve the precipitated iron oxide.

\section{Preparation of Czapex medium (CZ)}

The media was prepared by mixing $10 \mathrm{ml}$ of Czapek concentrate with $1 \mathrm{gm}$ of $\mathrm{K} 2 \mathrm{Hpo} 4$, $30.00 \mathrm{gm}$ of Sucrose, $17.5 \mathrm{gm}$ of Agar and the volume was completed to $1000 \mathrm{ml}$ by Distilled water. The medium was autoclaved at $121^{\circ} \mathrm{C}$ and 15 bar for $15 \mathrm{~min}$.

\section{Isolation, Purification and diagnosis of the contaminating fungi}

The primary isolation was performed by grinding $5 \mathrm{gm}$ of the pasta or chips samples using mortar and pistil to a fine powder, serial dilutions $\left(10^{-1}\right.$ to $\left.10^{-6}\right)$ were made, then the last three dilutions were obtained for isolation. The isolation was performed on PDA Petri plates in triplicates at $25 \pm 2{ }^{\circ} \mathrm{C}$ for 5-7 days. The fungal isolates were diagnosed morphologically by Dr. Abdulhafiz AlDabboun, Department of Marine Biology, Marine Sciences Centre according to Barnett \& Hunter (1972). The isolates of A. flavus were purified then kept in a diagonal position at a $4^{\circ} \mathrm{c}$ until use.

Calculation of the appearance and frequency percentages

The percentage of the appearance and frequency of each fungus was calculated according to the Gonzalez et al. (1995) equation:

The appearance $\%=\underline{\text { Number of species or geniuses appearances } \times 100}$

Total number of samples

The frequency $\%=\underline{\text { Number of species or geniuses colonies } \times 100}$

Total number of colonies 
Benyan \& Alhaddad / Basrah J. Agric. Sci., 32 (Special Issue): 314-322, 2019

Table (1) Percentage of appearance and frequency of the isolated fungi.

Isolated fungi

\begin{tabular}{lcc}
\hline Aspergillus oryzae & 3.75 & 0.46 \\
\hline Aspergillus alliaceus & 3.75 & 5.64 \\
\hline Aspergillus candidus & 3.75 & 0.28 \\
\hline Aspergillus fumigatus & 3.75 & 1.00 \\
\hline Aspergillus sclerotiorum & 3.75 & 9.07 \\
\hline Aspergillus flavus & 18.75 & 10.69 \\
\hline Aspergillus niger & 27.50 & 2.60 \\
\hline Alterraria alternate & 35.00 & 7.15 \\
\hline Pencillium sp. & 43.75 & \\
\hline
\end{tabular}

\section{Detection of aflatoxin B1}

UV light examination of aflatoxin B1 producing isolates of $A$. flavus

Eleven isolates of the A. flavus were grown in a $9 \mathrm{~cm}$ Petri dish containing coconut agar medium (3 replicates/isolate), then incubated in $27 \pm 1^{\circ} \mathrm{C}$ for five days. The cultures were examined under $365 \mathrm{~nm}$ wavelength of UV light to investigate possible ability to produce Aflatoxin (blue fluorescent colour), the examination was performed using the UV light device (Model UV, L21) (Yabe et al., 1987).

Examination of the ability of A. flavus isolates to produce Aflatoxin isolates ability to produce aflatoxin B1

\section{Ammonia vapor examination of aflatoxin B1 producing isolates of $A$. flavus}

The aflatoxin production ability of A. flavus isolates determined using ammonia vapor test by growing the fungus on coconut agar medium for seven days on $27 \pm 1^{\circ} \mathrm{C}$, then treated with $20 \%$ ammonia solution by placing a filter paper in the lid of a petri dish and saturate it with the ammonia solution. The dishes were incubated upside at $27 \pm 1^{\circ} \mathrm{C}$ then examined after one hour and 24 hours to observe the pink colour density (Saito \& Machida, 1999).

\section{Results \& Discussion}

Isolation Purification and diagnosis of the contaminating fungi

The isolation results (table 1; fig. 1) revealed the detection of nine species related to three main fungal genera Aspergillus spp., Pencillium sp., and Alternaria sp. Among isolated fungi, Penicillium sp. Showed the highest percent $(43.75 \%)$ followed by Alternaria alternata, A. niger and A. flavus, A. scelorotiorum, A. fumigatus, A. candidus, A. alliaceus and A. oryzae (35.00, 27.50, $18.75,3.75,3.75,3.75,3.75$ and $3.75 \%$ ) 
respectively, while the highest frequency percent was recorded by A. niger (10.96\%) followed by $A$. flavus, Pencillium sp., $A$. alliaceus, A. alternata, A. candidus, A. sclerotiorum, $A$. fumigatus and $A$. oryzae (9.07, 7.15, 5.64, 2.60, 1.28, 1.00, 0.46 and $0.46 \%)$ respectively. Among the isolated species, eleven A. flavus isolates (Puf1 A.f, Puf2 A.f, Indo1 A.f, Indo2 A.f, Indo1a A.f, Indo2a A.f, Indo2b A.f, Sha1 A.f, Sha2 A.f, Poch A.f, Far A.f) were targeted for next experiments (Table 2).

These results were corresponded with Qahtan (2002) results who isolated A. flavus from popcorn with other seven species of stored and field fungi, which indicating that the storage conditions can encourage the growth of storage fungi especially the Aspergilli that leads to produces Aflatoxins like aflatoxin B1 and cyclopiazonic acid (Payne et al.,1998; Horn et al., 2011; Alhaddad; 2013).

The UV test results (Table 2) showed that the examined isolates of $A$. flavus grouped into three main groups due to their ability to produce AFB1. The high production abilitygroup (++) were Puf1 A.f, Indo1 A.f, Indo2 A.f and Puf2 A.f; while the low production ability-group (+) were

Table (2): Examination of $A$. flavus.

\begin{tabular}{cccc}
\hline Isolate name & UV test & Ammonia test & $\begin{array}{c}\text { Isolation } \\
\text { Source }\end{array}$ \\
\hline Puf1 A.f & ++ & ++ & Chips \\
\hline Indo1 A.f & ++ & ++ & Pasta \\
\hline Indo2 A.f & ++ & ++ & Pasta \\
\hline Puf2 A.f & + & + & Chips \\
\hline Indo1a A.f & + & + & Pasta \\
\hline Indo2a A.f & + & + & Pasta \\
\hline Indo2b A.f & + & + & Pasta \\
\hline Sha1 A.f & + & + & Chips \\
\hline Poch A.f & + & + & Pop corn \\
\hline Sha2 A.f & - & - & Chips \\
\hline Far A.f & - & - & Chips \\
\hline
\end{tabular}


Benyan \& Alhaddad / Basrah J. Agric. Sci., 32 (Special Issue): 314-322, 2019

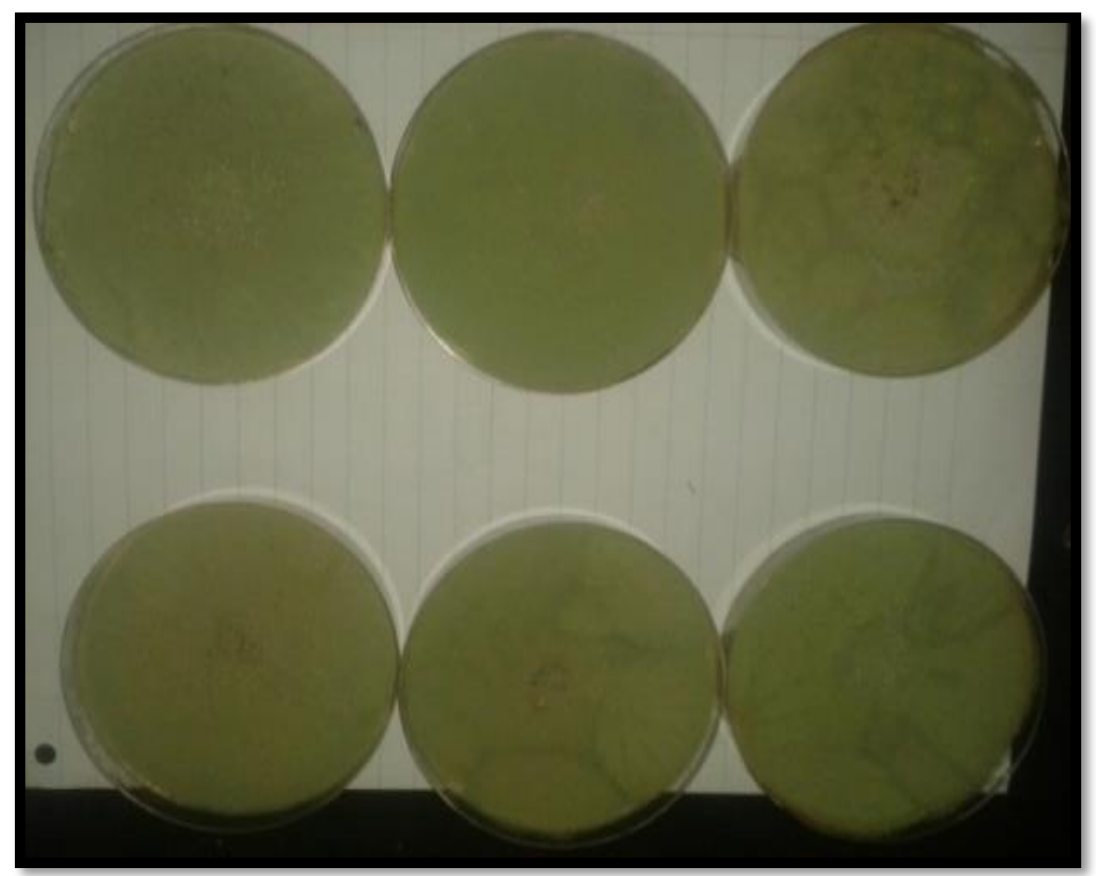

Fig. (1): Aspergillus flavus isolates on PDA medium.

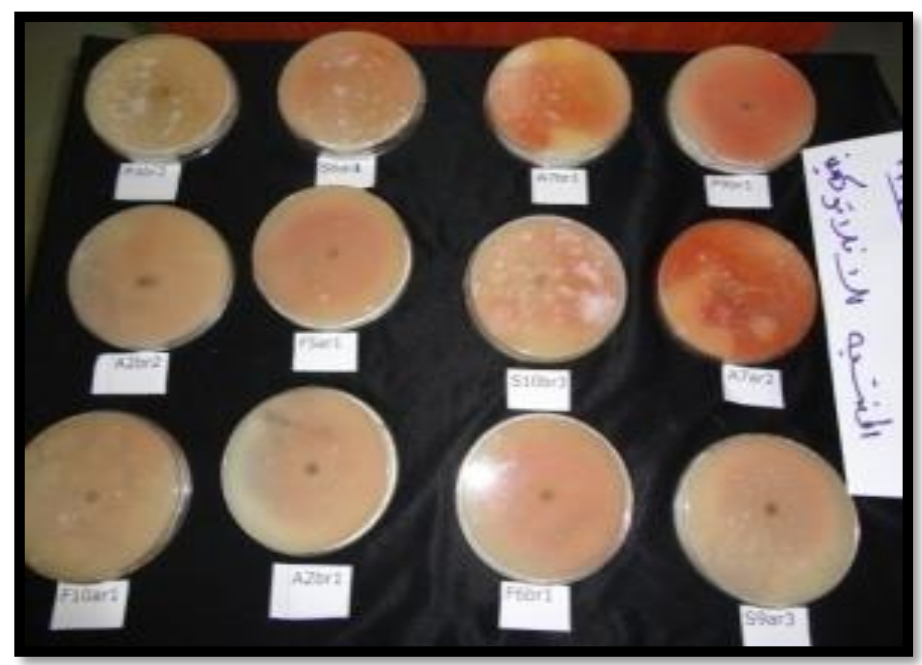

Fig. (2): Ammonia test to examine A.flavus isolates ability to produce aflatoxin B1.

Indo1a A.f, Indo2a A.f and Indo2b A.f, and non-aflatoxigenic group were Sha1 A.f and Poch A.f. The results of UV test were confirmed by ammonia test (Fig. 2).

\section{Conclusions}

Chips and pasta are contaminated with many fungi and fungi producing mycotoxins during processing and in poor storage conditions, In addition to contamination with Aspergillus flavus producing aflatoxins.

\section{Acknowledgements}

Many thanks to the Plant Protection Department for helping us provide some chemicals and glass materials. We also thank Prof. Dr. Abdul Hafez Aldubun to help in classification of fungi . 
Conflict of interest: The authors declare that they have no conflict of interest.

\section{References}

Alhaddad, A.A. (2013). Investigation on associated fungi to some of dried fruits and strains of Aspergillus flavus producted to Aflatoxine B1 and destruction ability with use some of physical methods in Basra. M. Sc. Thesis. Coll. Agriculture, Univ.Basrah. $100 \mathrm{pp}$.

Barnett, H.L., \& Hunter, B.B. (1972). Illustrated Genera of Imperfect Fungi, $3^{\text {rd }}$ ed. Burgess Publishing Company. Washington. D.C.: 241pp.

Bhat, R.V. \& Krishnamachari, K.A. (1977). Follow-up study of aflatoxic hepatitis in parts of western India. Indian J. Med. Res., 66: 55-58.

Bhat, R.V. \& Vasanthi; S. (2003). Food safety in food Security and food trade: Mycotoxin food safety risking developing countries. Inte. Food Poli. Rese. Inst.10 (17) : 1-2.

Bryden, W.L. (2012). Mycotoxin contamination of the feed supply chain :Implication for animal productivity and feed security. Anim. Feed Sci. Technol., 173(1-2): 134-158.

Carvajal, M. (2015). Metabolic changes of Aflatoxin B1 to become an active carcinogen and the control of this Toxin. Immunome Res., 11: 1745-7580.

Davis, N.D.; Diener, U.L., \& Agnihotri, V.P. (1967). Production of aflatoxin $B_{1}$ and $G_{1}$ in chemically defined medium. Mycopath. Mycol. Appl., 31: 251-253.

Da Rocha, M.E.B.; Freire, F.C.O; Maia, F.E.F.,Guedes, M.I.F.; Rondina D.(2014). Mycotoxins and their effect on humans and animal Health.Food Control.36:159-165.
Gonzalez, H.H.L.; Resnik, S.L.; Boca, R.T. \& Marasas, W.F.O. (1995). Mycoflora of Argentinian corn harvested in the main production area in 1990. Mycopathologia,130: 29-36.

Horn, B.W.; Moore, G.C. \& Carbone, I. (2011) Sexual reproduction in aflatoxinproducing Aspergillus nomius Mycologia 103: 174-183 .

Jaimez, J.; Fente, C.A.; Vazquez, B.I.; Franco, C.M. \& Cepeda, A. (2000). Application of the assay of aflatoxins by liquid chromatography with fluorescence detection in food analysis. J Chromatogr., A. $882: 1-10$

Klich, M.A. (2002). Identification of Common on Aspergillus sp. Cambridge Univ: 116pp.

Loveland, P.M.; Wilcox, J.S.; Hadricks, J.D. \& Bailey, G.S. (1988). Comparative metabolism and DNA bindind of aflatoxin $\mathrm{B}$ aflatatoxin $\mathrm{M}_{1}$ aflatoxical and aflatoxical . $\mathrm{M}_{1}$ inheptocytes from raibow trout (Salmo gairdneri). Carcinogensis, 9: 441-446.

Marin, S.; Ramos, A.J.; Cano-Sancho, G. \& Sanchis, V. (2013) Mycotoxins: Occurrence, toxicology, and exposure assessment. Food Chem. Toxicol., 60: 218237.

Makun, H.A.; Anjorin, S.T.M.; Oronfoye, B.; Adejo, F.O.; Afolbi, F.; Galogun, B.O. \& Surajudeer, A.A. (2010). Fungal and Aflatoxin contamination of some human food commodities in Nigeria .Afr. J. Food Sci., 4(4): 127-135.

Milani, J.M. (2013) Ecological conditions affecting mycotoxin production in cereals: A review Vet. Med. Czech Repub., 58: 405-411. 
Nakai, V.K.; Rocha, L.O.; Gonçalez, E.; Fonseca, H. \& Ortega, E.M.M. (2008) Distribution of fungi and aflatoxins in a stored peanuts variety. Food Chem., 106: 285-290.

Payne, G.A.; Sinha K.K. \& Bhatnagar, D.M. (1998). Process of contamination by aflatoxin producing fungi and their impacts on crops. 279-300. In Sinha, K.K. \& Bhatnagar, D. (Eds.). Mycotoxins in Agriculture and food safety Decker. Inc. New York: 520pp.

Qahtan, F.A. (2002). Detection of Aflatoxin $\mathrm{B} 1$ and B2, and ochratoxin A in maize and some of its products. M. Sc. Thesis. Coll. Agriculture Univ. Baghdad. 95 pp.

Rastogi, S.C.; Heydorn, S.; Johansen, J.D. \& Basketter, D.A. (2001) Fragrance chemicals in domestic and occupational products. Contact Dermatitis, 45: 221-225.

Reddy, S.V. \& Farid, W. (2006). Properties of aflatoxin and it producing fungi. Int. Food Policy Res. Institute, 3: 127-204.

Rustom, I.Y.S. (1997). Aflatoxin in food and feed: Occurrence, legislation and inactivation by physical methods. Food Chem., 59: 57-67.

Rustom, I.Y.S.; López-Leiva, M.H. \& Nair, B.M. (1993). Effect of $\mathrm{pH}$ and heat treatment on the mutagenic activity of peanut beverage contaminated with aflatoxin. Food Chem., 46: 37-42.

Saito, M. \& Machida, S. (1999). A rapid identification method for aflatoxin producing strains of Aspergillus flavus and Aspergillus parasiticus by ammonia vapour. Mycoscience, 40: 205-208.

Smith, J.E.; Solomons, G.L.; Lewis, C.W. \& Anderson, J.G. (1994). Mycotoxins in human nutrition and health. Brussels:
European Commission CG XII3(4): 187192.

Yabe, K.Y.; Ando, Y.; Ito, M. \& Terkado, N. (1987). Simple method for screening aflatoxin-producing molds by U.V. Photography Applied and Environmental Microbiology, 53: 230-234. 